\title{
Anticancer Efficacy of Cordyceps militaris Ethanol Extract in a Xenografted Leukemia Model
}

\author{
Jae Gwang Park, ${ }^{1}$ Young-Jin Son, ${ }^{2}$ Tae Ho Lee, ${ }^{3}$ Nam Joon Baek, \\ Deok Hyo Yoon, ${ }^{4}$ Tae Woong Kim, ${ }^{5}$ Adithan Aravinthan, ${ }^{6}$ Sungyoul Hong, \\ Jong-Hoon Kim, ${ }^{6}$ Gi-Ho Sung, ${ }^{4}$ and Jae Youl Cho ${ }^{1}$ \\ ${ }^{1}$ Department of Genetic Engineering, Sungkyunkwan University, Suwon 16419, Republic of Korea \\ ${ }^{2}$ Department of Pharmacy, Sunchon National University, Suncheon 57922, Republic of Korea \\ ${ }^{3}$ Functional Food \& Phytomedicine Research Strategic Project Team, Research Planning \& Management Department, \\ Dong-A ST, Yongin 17073, Republic of Korea \\ ${ }^{4}$ Institute for Bio-Medical Convergence, International St. Mary's Hospital and College of Medicine, \\ Catholic Kwandong University, Incheon, Republic of Korea \\ ${ }^{5}$ Biochemistry, Kangwon National University, Chuncheon 24341, Republic of Korea \\ ${ }^{6}$ Department of Veterinary Physiology, College of Veterinary Medicine, Biosafety Research Institute, \\ Chonbuk National University, Iksan 54596, Republic of Korea
}

Correspondence should be addressed to Jong-Hoon Kim; jhkim1@jbnu.ac.kr, Gi-Ho Sung; sung97330@gmail.com, and Jae Youl Cho; jaecho@skku.edu

Received 9 February 2017; Revised 17 May 2017; Accepted 30 May 2017; Published 6 July 2017

Academic Editor: Youn C. Kim

Copyright (C) 2017 Jae Gwang Park et al. This is an open access article distributed under the Creative Commons Attribution License, which permits unrestricted use, distribution, and reproduction in any medium, provided the original work is properly cited.

Cordyceps militaris is used widely as a traditional medicine in East Asia. Although a few studies have attempted to elucidate the anticancer activities of $C$. militaris, the precise mechanism of $C$. militaris therapeutic effects is not fully understood. We examined the anticancer activities of $C$. militaris ethanolic extract (Cm-EE) and its cellular and molecular mechanisms. For this purpose, a xenograft mouse model bearing murine $\mathrm{T}$ cell lymphoma (RMA) cell-derived cancers was established to investigate in vivo anticancer mechanisms. MTT [3-(4,5-dimethylthiazol-2-yl)-2,5-diphenyltetrazolium bromide] assay, immunoblotting analysis, and flow cytometric assay were employed to check in vitro cytotoxicity, molecular targets, and proapoptotic action of Cm-EE. Interestingly, cancer sizes and mass were reduced in a C. militaris-administered group. Levels of the phosphorylated forms of $\mathrm{p} 85$ and AKT were clearly decreased in the group administered with $\mathrm{Cm}$-EE. This result indicated that levels of phosphoglycogen synthase kinase $3 \beta$ (p-GSK3 $\beta$ ) and cleaved caspase- 3 were increased with orally administered Cm-EE. In addition, Cm-EE directly inhibited the viability of cultured RMA cells and C6 glioma cells. The number of proapoptotic cells was significantly increased in a $\mathrm{Cm}$-EE treated group compared with a control group. Our results suggested that $C$. militaris might be able to inhibit cancer growth through regulation of p85/AKT-dependent or GSK3 $\beta$-related caspase-3-dependent apoptosis.

\section{Introduction}

Cordyceps species are mushrooms that are mainly produced on hosts such as insects. Cordyceps species are useful natural products with a variety of biological activities $[1,2]$. Cordyceps militaris, which is a parasite on moth caterpillar larvae, is used broadly in East Asia as a traditional medicine [3]. However, commercializing this mushroom is difficult because it is very rare in nature. Recently, a cultivation process for C. militaris was successfully established [4]. This mushroom has received attention as a health supplement to improve longevity, endurance, and human health and as an alternative medicine to ameliorate diseases including stroke, sore throat, tuberculosis, epilepsy, and cancer [5-7]. Many active compounds such as mannitol, ergosterol, polysaccharides, and cordycepin have been identified from C. militaris, and studies with these compounds showed diverse pharmacological 
activities with antiviral, antioxidative, antidiabetic, antiinflammatory, antiplatelet aggregation, and anticancer effects [8-12]. Although many systemic studies on biological activities of $C$. militaris have been conducted, the pharmacological value of $C$. militaris has not been fully clarified. Therefore, we used a xenograft mouse model bearing murine $\mathrm{T}$ cell lymphoma (RMA) cell-derived leukemia to determine the anticancer activity of $C$. militaris ethanolic extract (Cm-EE) and establish its molecular mechanism.

\section{Materials and Methods}

2.1. Materials. Cordyceps militaris was provided by MushTech (Chuncheon, Korea). RMA and rat C6 glioma cells were from American Type Culture Collection (Manassas, VA) and 3-(4-5-dimethylthiazol-2-yl)-2-5-diphenyltetrazolium bromide (MTT) and hematoxylin and eosin were from SigmaAldrich (St. Louis, MO, USA). FITC-Annexin V Apoptosis Detection Kits were from eBioscience (San Diego, CA, USA). RPMI and fetal bovine serum (FBS) were from GIBCO (Grand Island, NY, USA). Total or phosphospecific antibodies against p85, AKT, glycogen synthase kinase $3 \beta$ (GSK3 $\beta$ ), and caspase- 3 were from Cell Signaling (Beverly, MA, USA).

2.2. Cell Culture. C6 glioma and RMA cells were cultured in RPMI 1640 supplemented with 10\% heat-inactivated FBS and $1 \%$ antibiotics (penicillin and streptomycin) at $37^{\circ} \mathrm{C}$ under $5 \%$ $\mathrm{CO}_{2}$. For experiments with C6 cells, trypsin/EDTA solution was used to detach cells and $2 \times 10^{6}$ cells/ml were used.

2.3. Drug Treatment. Cm-EE powder was suspended in $0.5 \%$ sodium carboxymethyl cellulose ( $\mathrm{Na}-\mathrm{CMC}$ ) for in vivo experiments. For in vitro experiments, Cm-EE powder was liquefied in $100 \%$ DMSO at $100 \mathrm{mg} / \mathrm{ml}$, and the stock solution was diluted with culture medium, as previously reported [13].

2.4. Xenograft Mouse Model Experiment. All animal experiments were carried out in accordance with guidelines of the National Research Council's Guide (IACUC, Republic of Korea) for the Care and Use of Laboratory Animals. The experimental protocol was approved by the Animal Experiments Committee of Sungkyunkwan University. Our xenograft animal model was established using C57BL/6 mice (male, five weeks old; Orient, Republic of Korea), as reported previously $[14,15]$. Mice were housed individually on a 12 $\mathrm{h}$ day/night cycle at $23-27^{\circ} \mathrm{C}$ with access to food and water. Mice were randomly divided into two groups ( $n=14 /$ group): (1) a vehicle-control group $(n=10)$ in which animals were orally administered $0.5 \% \mathrm{Na}-\mathrm{CMC}$ and (2) a Cm-EE treatment group $(n=10)$ in which animals were orally administered Cm-EE (20 mg/kg). Mice were injected with RMA cells $\left(1 \times 10^{6}\right.$ cells per animal) subcutaneously in the back next to the right hind leg. After induction of cancer, oral administration of Cm-EE or vehicle was from day 1 to day 21. Cancer sizes for groups were measured with a standard caliper. Cancer volume was calculated as follows: cancer volume $\left(\mathrm{mm}^{3}\right)=\left[\right.$ cancer length $(\mathrm{mm}) \times$ cancer width $\left.(\mathrm{mm})^{2}\right] / 2$. On day 25 , mice were sacrificed.
2.5. Preparation of Total Lysates from Cancer or Cultured Cells and Immunoblotting. C6 glioma cultured cells or cancer tissues were washed three times in cold PBS with $1 \mathrm{mM}$ sodium orthovanadate. Samples were lysed as previously described $[16,17]$ via suspension in lysis buffer $(20 \mathrm{mM}$ Tris- $\mathrm{HCl}, \mathrm{pH}$ 7.4, 2 mM EDTA, 2 mM ethyleneglycotetraacetic acid, $50 \mathrm{mM}$ $\beta$-glycerol phosphate, $1 \mathrm{mM}$ sodium orthovanadate, $1 \mathrm{mM}$ dithiothreitol, $1 \%$ Triton X-100, 10\% glycerol, $10 \mu \mathrm{g} / \mathrm{ml}$ aprotinin, $10 \mu \mathrm{g} / \mathrm{ml}$ pepstatin, $1 \mathrm{mM}$ benzimide, and $2 \mathrm{mM}$ PMSF) for $30 \mathrm{~min}$ with rotation at $4^{\circ} \mathrm{C}$. Total lysates were clarified by centrifugation at $13,000 \times \mathrm{g}$ for $10 \mathrm{~min}$ at $4^{\circ} \mathrm{C}$ and stored at $-20^{\circ} \mathrm{C}$. Total lysates were subjected to Western blotting for total $\mathrm{p} 85, \mathrm{AKT}, \mathrm{GSK} 3 \beta$, and $\beta$-actin; phosphoforms of $\mathrm{p} 85$, $\mathrm{AKT}$, and GSK $3 \beta$; and cleaved caspase-3. Protein levels were visualized as previously reported [13].

2.6. HPLC Analysis. For determination of the active components in $\mathrm{Cm}-\mathrm{EE}$, high-performance liquid chromatography (HPLC) was conducted as stated previously [18].

2.7. Determination of Viability and Apoptosis. Cytotoxicity of Cm-EE on RMA and C6 cells was evaluated by conventional MTT assays, as previously described [19, 20]. Cells were preincubated in 96-well plates at $1 \times 10^{5}$ cells/well for $18 \mathrm{~h}$ and treated with indicated concentrations of Cm-EE (0 to $200 \mu \mathrm{g} / \mathrm{ml}$ ) for $24 \mathrm{~h}$. Absorbance was measured using a microplate reader at $540 \mathrm{~nm}$. To assess apoptosis, nucleic acid dye 7-amino-actinomycin D-(7-AAD) and Annexin V were used in flow cytometric assays to verify early apoptotic cells.

2.8. Evaluation of Tumorigenesis. C6 cells were grown to a monolayer in $60-\mathrm{mm}$ plates for wound healing assays. Wounds were generated as previously reported [21] by scratching the monolayer with a p200 pipette tip. Variation in the scratched monolayer was observed with a microscope (Olympus, Tokyo, Japan). For the invasion assays, the invasive ability of C6 cells was measured as described previously using Matrigel-coated plates [21]. After incubation with Cm-EE for $24 \mathrm{~h}$, cells were fixed in $4 \%$ formaldehyde; hematoxylin and eosin was used to stain cells that successfully penetrated the Matrigel layer [22].

2.9. Statistical Analysis. All data presented in this paper are mean \pm standard deviation (SD) of experiments performed with 10 mice (Figures 1(a), 1(b), and 1(c)) or six replicates (Figure 2). Results were analyzed with Kruskal-Wallis/MannWhitney tests for statistical comparisons. $p<0.05$ was considered statistically significant. All statistical tests were carried out using SPSS (Version 22.0, 2013, IBM Corp., Armonk, NY, USA).

\section{Results and Discussion}

A few studies on the anticancer activity of $C$. militaris have been reported [5-7]. However, the precise reasons for cancer suppression by $C$. militaris have not been elucidated. Therefore, we considered it important to establish the anticancer mechanism of C. militaris. We constructed a xenograft mouse model bearing RMA cell-derived cancer to identify the cause 

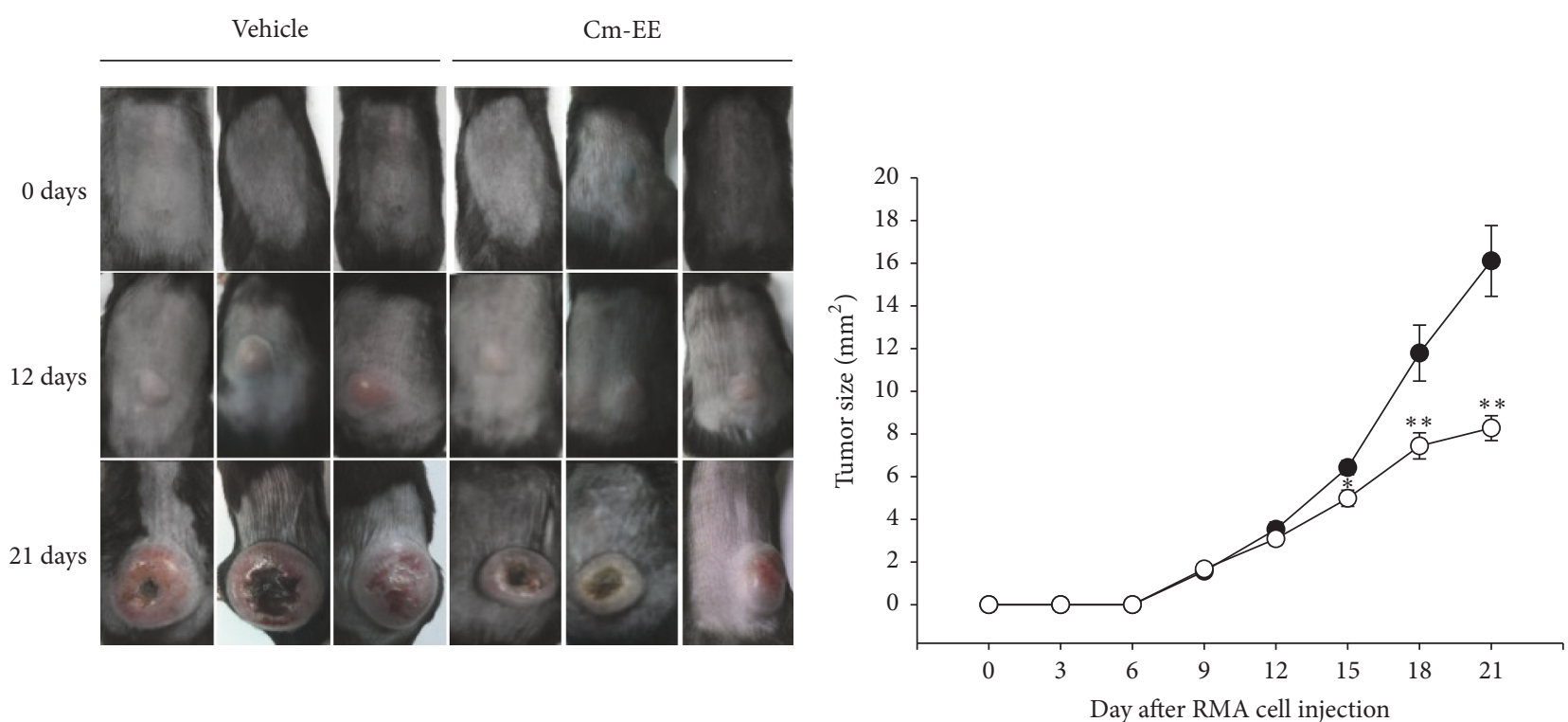

- Vehicle

$-\mathrm{O}-\mathrm{Cm}-\mathrm{EE}$

(a)

(b)

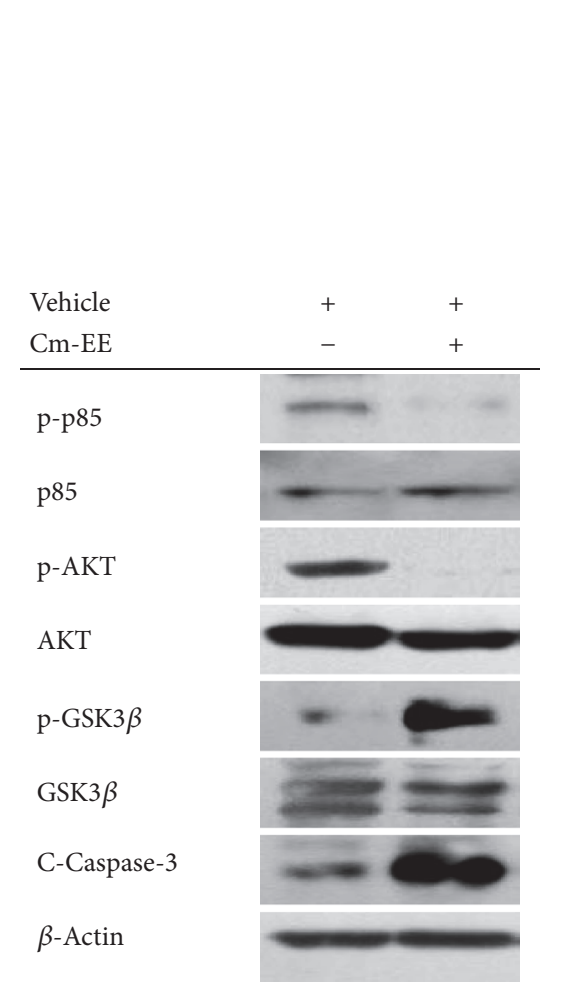

(c)
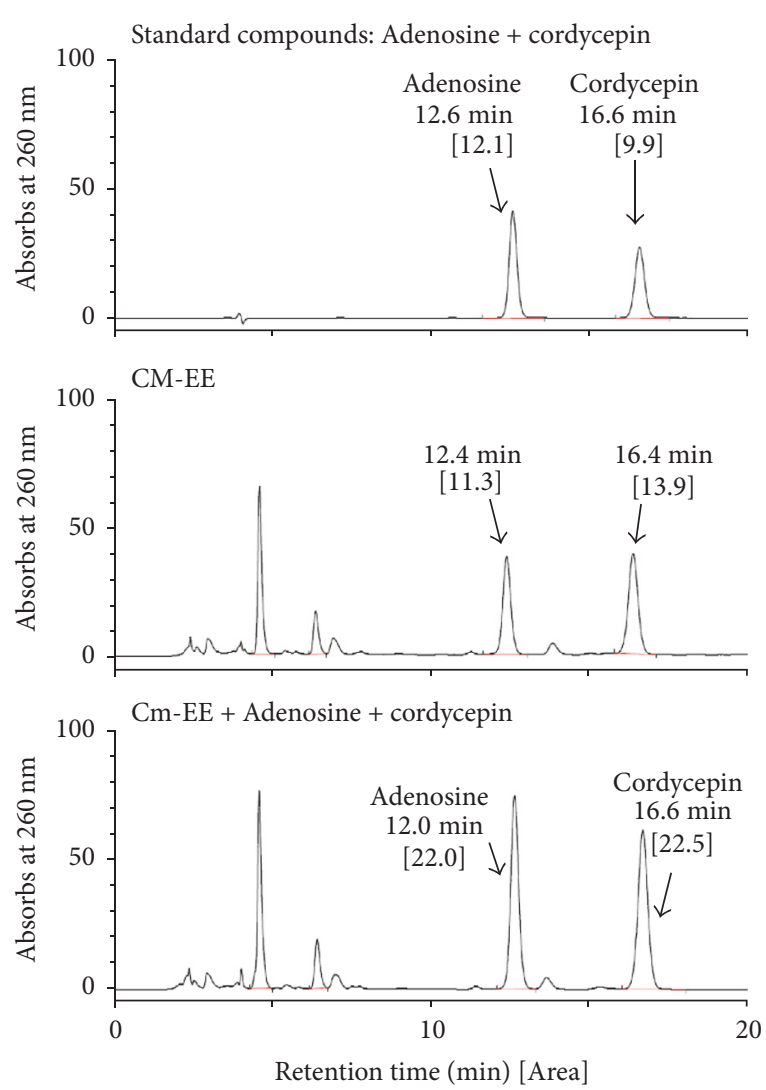

(d)

FIGURE 1: Anticancer activity of Cm-EE in a xenograft mouse model with RMA cell-derived cancer. RMA cells $\left(1 \times 10^{6}\right.$ cells per mouse $)$ were injected subcutaneously into backs next to right hind legs. Mice with RMA cells were sorted into groups ( $n=10 /$ group) for orally administrated $\mathrm{Cm}-\mathrm{EE}(20 \mathrm{mg} / \mathrm{kg})$ or vehicle. (a) Tumors grown in xenograft mouse model with RMA cell-derived cancer were taken by a digital camera. (b) Induced tumor sizes were measured at indicated days until experiment end. (c) Effect of $\mathrm{Cm}$-EE on proteins in apoptotic pathways was evaluated through determining the levels of total and phosphorylated Akt, p85, GSK3 $\beta$, cleaved caspase-3, and $\beta$-actin in tumor tissues by immunoblotting analysis. (d) Phytochemical finger printing of Cm-EE was evaluated by HPLC analysis. ${ }^{*} p<0.05$ and ${ }^{* *} p<0.01$ compared with control. 


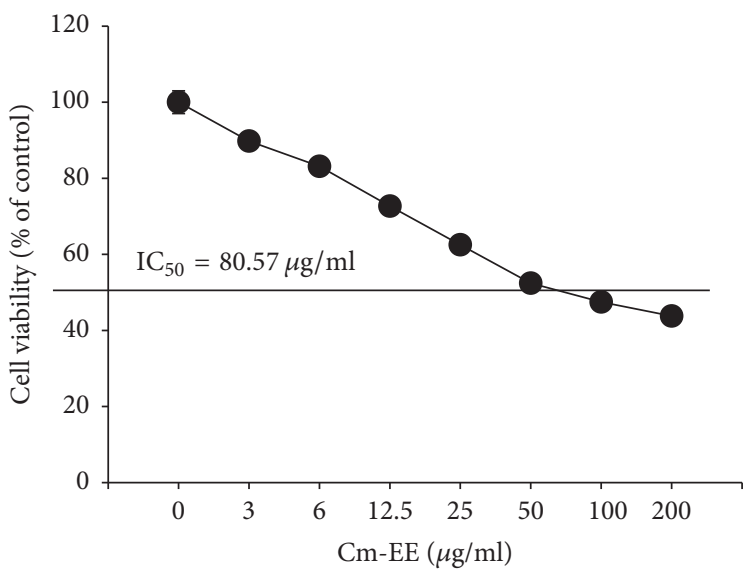

(a)
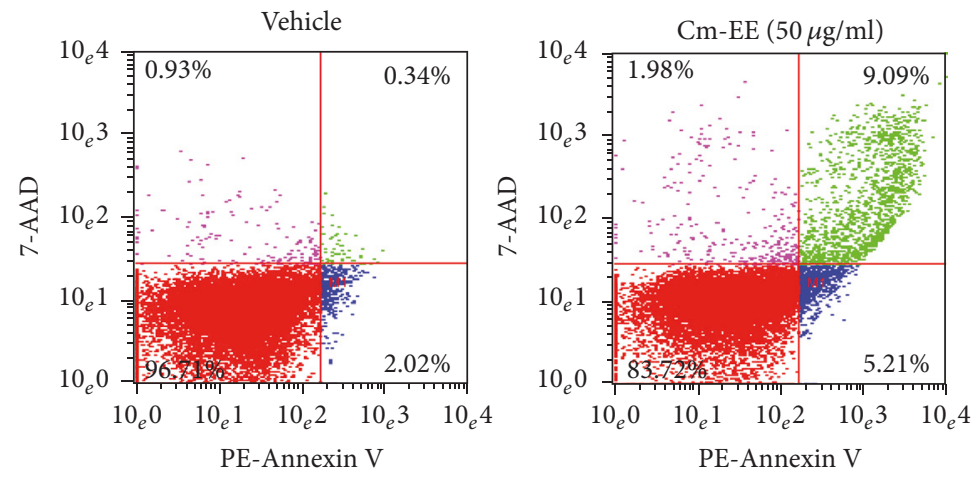

(b)

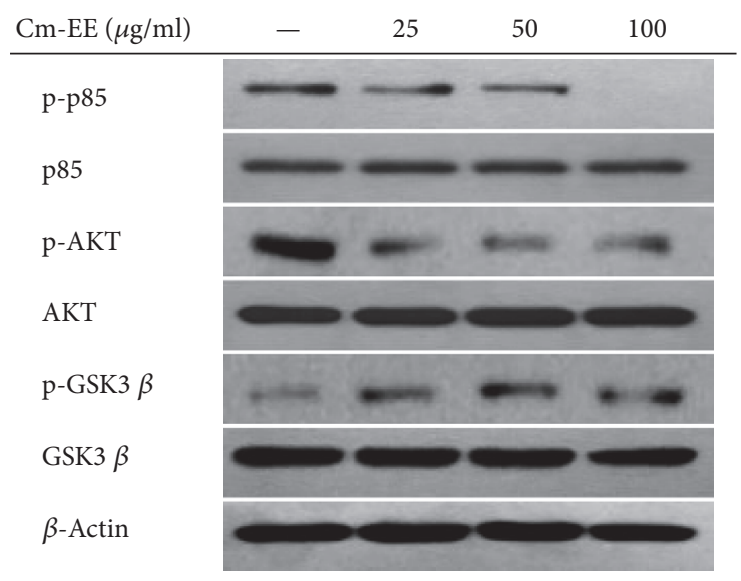

(c)

Figure 2: Effect of Cm-EE on apoptotic cell death and survival pathways. (a) RMA cells $\left(2 \times 10^{6}\right.$ cells/ml $)$ were incubated with Cm-EE for $24 \mathrm{~h}$. Viability of RMA cells was then evaluated by MTT assays. (b) Cell apoptosis was determined by Annexin V/7ADD staining. Annexin V (right lower quadrant) and Annexin $\mathrm{V}^{+} / 7 \mathrm{AAD}^{+}$(right upper quadrant) cells indicate early apoptotic and late apoptotic cell levels. The levels of Cm-EE-treated apoptotic cells were evaluated by flow cytometry. (c) Levels of phosphorylated Akt, p85, and GSK3 $\beta$ in Cm-EE-treated RMA cells were detected by immunoblotting assays.

of Cm-EE anticancer activity. Over time, tumors in a C. militaris-administered group were less developed than tumors in a vehicle-administered group (Figures 1(a) and 1(b)). These results confirmed that cultivated $C$. militaris exhibited anticancer activity similar to other natural products such as Korean red ginseng and wild ginseng $[14,15,23]$.

Different Cordyceps species have been studied to elucidate pharmacological activity including anti-inflammatory, antioxidant, antifungal, and anticancer activity. Cordyceps sinensis species inhibits growth of U937 leukemia, A549 lung cancer, and B16 melanoma cells [24-26]. Cordyceps militaris inhibits growth of HepG2 liver hepatocellular carcinoma cells [5]. Therefore, previous results indicate that Cordyceps species have potent anticancer activity against diverse cancer types including leukemia, melanoma, lung carcinoma, and liver carcinoma.

We investigated the cause of inhibited cancer tissue generation by $C$. militaris. To investigate if $\mathrm{Cm}-\mathrm{EE}$ anticancer activity was mediated through cell survival and death processes, protein levels were determined by immunoblotting using antibodies against cleaved caspase-3, phospho-p85, phospho$\mathrm{AKT}$, and phospho-GSK3 $\beta$ [27-29]. The levels of phosphorylated p85 and AKT were significantly decreased in a group given $\mathrm{Cm}$-EE. In contrast, levels of phosphorylated GSK3 $\beta$ and cleaved caspase- 3 were increased in the group administered Cm-EE (Figure 1(c)). The phospho-p85/Akt pathway is reported to be involved in signals related to cell growth and death. Stimulation of this cascade prevents apoptosis $[6,27$, 30]. GSK $3 \beta$ is a serine-threonine protein kinase involved in glycogen synthesis. GSK3 $\beta$ reportedly has opposing functions, inducing cell apoptosis while maintaining cell survival and proliferation [28]. In our results, accumulation of an active form of GSK3 $\beta$ in a group administered Cm-EE seemed to be caused by inhibiting AKT phosphorylation, but the cause was not fully elucidated. We propose that the anticancer activities of $\mathrm{Cm}-\mathrm{EE}$ were derived from induction of cancer-cell apoptosis through p85/AKT or GSK $3 \beta$ signaling pathways. To determine if $\mathrm{Cm}$-EE suppressed cell proliferation directly, we used MTT assays and cultured RMA cells. Cm-EE dose-dependently reduced the viability of RMA 


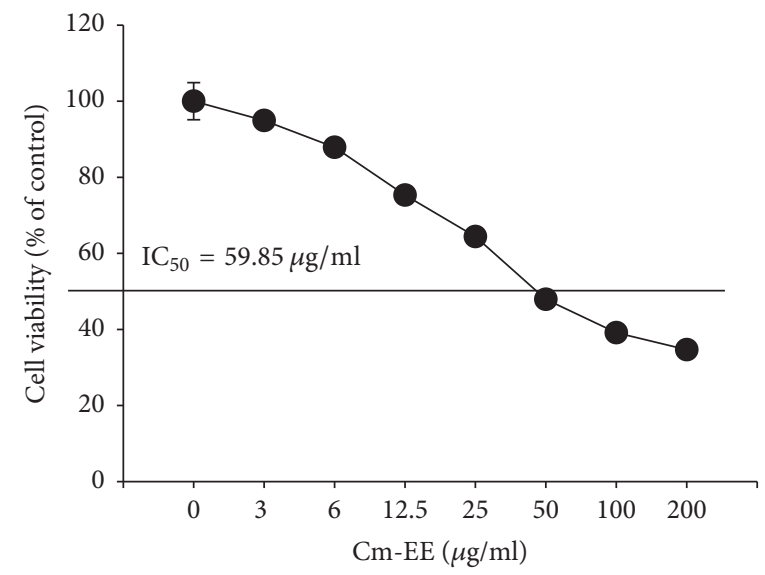

(a)

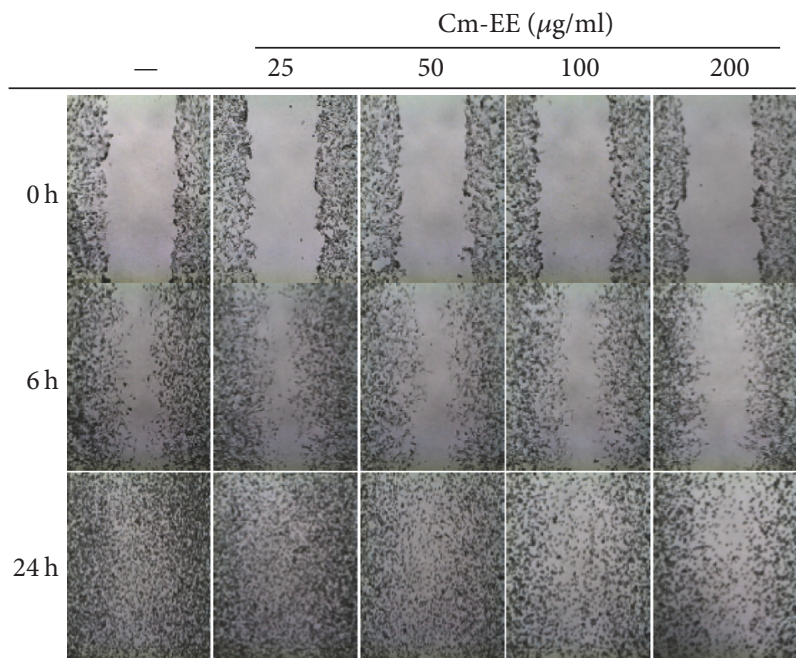

(A)

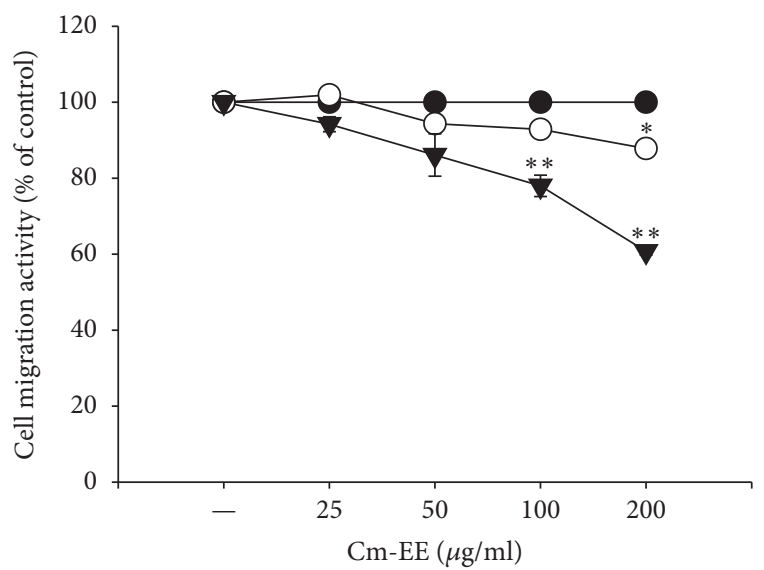

(B)

(b)

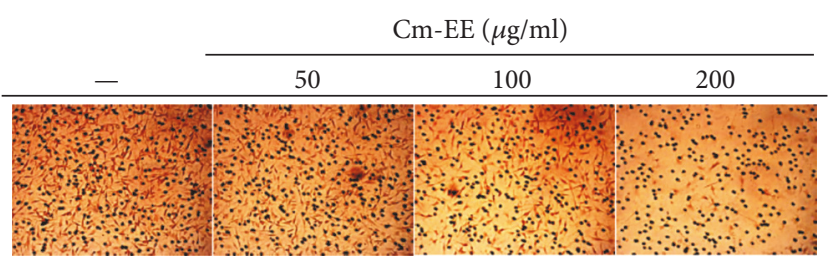

(A)

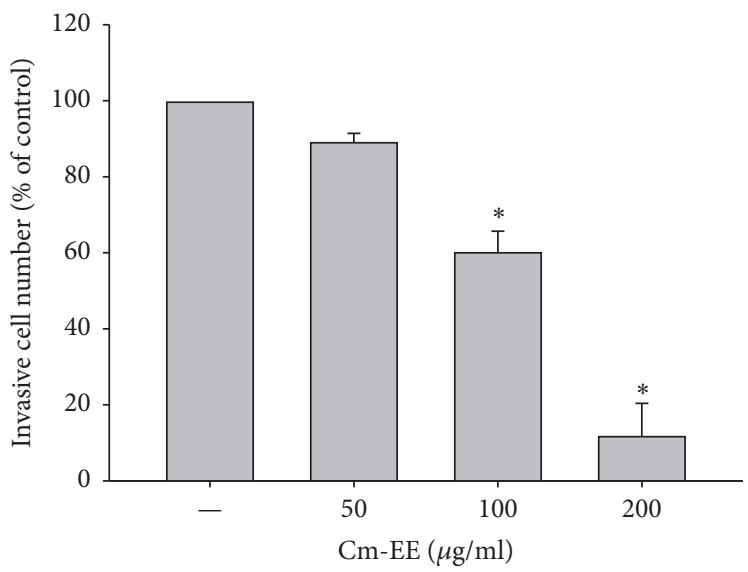

(B)

(c)

FiguRE 3: Effect of Cm-EE on tumorigenic responses. (a) C6 glioma cells $\left(2 \times 10^{6}\right.$ cells/ml $)$ incubated with Cm-EE for $24 \mathrm{~h}$. Viability of RMA cells was evaluated by MTT assays. (b) Effect of Cm-EE on migration was measured by wound healing assay. (c) The invasion capacity of C6 cells under Cm-EE exposure was analyzed by hematoxylin and eosin staining and quantitatively evaluated by counting the Matrigel layerinvaded cells (B). Photographs were taken with a digital camera (A). Means of migrated and invasive cells were measured by ImageJ software. ${ }^{*} p<0.05$ and ${ }^{* *} p<0.01$ compared with control. 


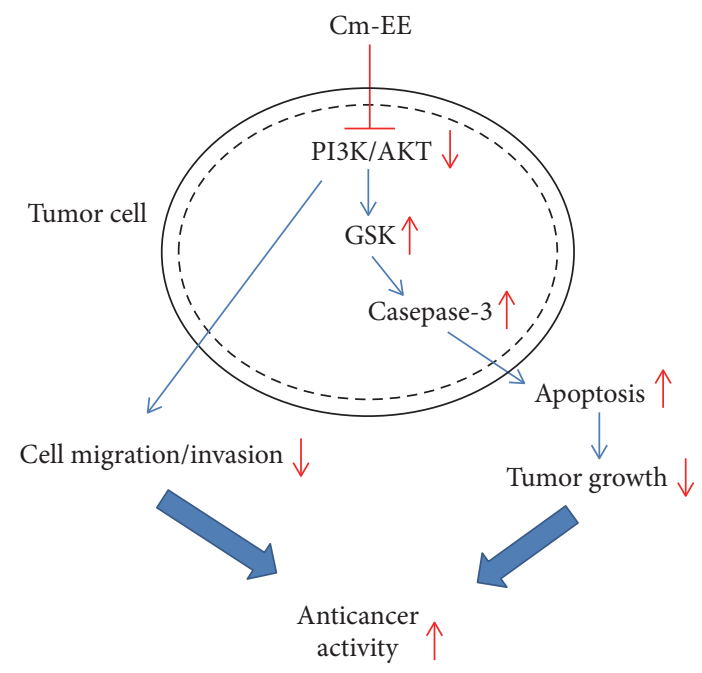

FIgURE 4: Putative mechanism of Cm-EE-mediated anticancer responses. GSK3 $\beta$ : glycogen synthase kinase $3 \beta$; PI3K: phosphatidylinositol 3 kinase; and Cm-EE: Cordyceps militaris ethanolic extract.

cells (Figure 2(a)). To confirm whether cell death was due to apoptosis, flow cytometric assays using Annexin V/7AAD dyes was conducted. The amount of only Annexin V staining [propidium iodide (PI)/7-AAD negative], indicating early stages of apoptosis [31], was increased with Cm-EE treatment (Figure 2(b)). Levels of proteins related to cell apoptosis, specifically phosphorylated p85, AKT, and GSK $3 \beta$, were similar to results from in vivo experiments (Figure 2(c)).

To determine if the anticancer ability of Cm-EE affected growth or death of other cancer cells, we used cell viability tests and invasion and migration assays with C6 glioma cells under Cm-EE treatment conditions. Similar to the previous results of this study, the viability of C6 cells was dosedependently reduced by Cm-EE (Figure 3(a)). In addition, Cm-EE abated the migration of C6 glioma cells (Figure 3(b)) and blocked invasion (Figure 3(c)). Based on these results, we suggest that $C$. militaris has anticancer activities such as suppression of cell migration and invasion through stimulation of $\mathrm{p} 85 / \mathrm{AKT}$ or GSK $\beta$-related apoptotic procedures. How $\mathrm{Cm}$-EE regulates p85/AKT or GSK $\beta$-related apoptosis is not fully understood. Therefore, we will study the regulatory mechanism of p85/AKT or GSK $\beta$-related caspase-3dependent apoptosis via $C$. militaris in the future. Many active compounds such as mannitol, ergosterol, polysaccharides, and cordycepin have been identified from C. militaris [8-12]. However, anticancer mechanism studies using these compounds seem to be insufficient. Based on these results, future studies will determine a more accurate mechanism for the anticancer activity of $C$. militaris.

In summary, $\mathrm{Cm}$-EE has potent anticancer activity in a xenograft mouse model with RMA cell-derived tumors. Immunoblot analysis showed that apoptotic signaling elements such as p-p85, p-AKT, p-GSK3 $\beta$, and cleaved caspases3 were regulated as summarized in Figure 4 . The number of proapoptotic cells in a $C$. militaris-treated group significantly increased compared with a control group using cultured
RMA cells. Cm-EE significantly increased the number of proapoptotic cultured RMA cells and reduced the migration and invasive ability of C6 glioma cells. Our results suggested that $C$. militaris might have a strong ability to inhibit cancer growth through regulation of p85/AKT or GSK3 $\beta$-related caspase-3-dependent apoptosis.

\section{Disclosure}

The authors alone are responsible for the content and writing of the paper.

\section{Conflicts of Interest}

The authors report no conflicts of interest.

\section{Authors' Contributions}

Jae Gwang Park and Young-Jin Son equally contributed to this work.

\section{Acknowledgments}

This work was performed with the support of the Cooperative Research Program for Agriculture Science \& Technology Development (Project no. PJ009241), Rural Development Administration, Korea.

\section{References}

[1] T. B. Ng and H. X. Wang, "Pharmacological actions of Cordyceps, a prized folk medicine," Journal of Pharmacy and Pharmacology, vol. 57, no. 12, pp. 1509-1519, 2005.

[2] X. Zhou, Z. Gong, Y. Su, J. Lin, and K. Tang, "Cordyceps fungi: natural products, pharmacological functions and developmental products," Journal of Pharmacy and Pharmacology, vol. 61, no. 3, pp. 279-291, 2009.

[3] S. P. Wasser, "Medicinal mushrooms as a source of antitumor and immunomodulating polysaccharides," Applied Microbiology and Biotechnology, vol. 60, no. 3, pp. 258-274, 2002.

[4] B. Shrestha, S. Han, W. Lee, S. Choi, J. Lee, and J. Sung, "Distribution and," Mycobiology, vol. 33, no. 4, pp. 178-181, 2005.

[5] Y. K. Rao, S.-H. Fang, W.-S. Wu, and Y.-M. Tzeng, "Constituents isolated from Cordyceps militaris suppress enhanced inflammatory mediator's production and human cancer cell proliferation," Journal of Ethnopharmacology, vol. 131, no. 2, pp. 363-367, 2010.

[6] D.-H. Lee, H.-H. Kim, and H.-J. Cho, "Cordycepin-Enriched WIB801C from Cordyceps militaris inhibits collagen-induced [Ca2+] i mobilization via cAMP-dependent phosphorylation of inositol 1, 4, 5-trisphosphate receptor in human platelets," Biomolecules Therapeutics, vol. 22, pp. 223-231, 2014.

[7] Y.-X. Gu, Z.-S. Wang, S.-X. Li, and Q.-S. Yuan, "Effect of multiple factors on accumulation of nucleosides and bases in Cordyceps militaris," Food Chemistry, vol. 102, no. 4, pp. 13041309, 2007.

[8] S. Y. Lee, T. Debnath, S.-K. Kim, and B. O. Lim, "Anti-cancer effect and apoptosis induction of cordycepin through DR3 pathway in the human colonic cancer cell HT-29," Food and Chemical Toxicology, vol. 60, pp. 439-447, 2013. 
[9] L. Lim, C. Lee, and E. Chang, "Optimization of solid state culture conditions for the production of adenosine, cordycepin, and d-mannitol in fruiting bodies of medicinal caterpillar fungus cordyceps militaris (L.:Fr.) link (Ascomycetes)," International Journal of Medicinal Mushrooms, vol. 14, no. 2, pp. 181-187, 2012.

[10] X.-B. Mao and J.-J. Zhong, "Hyperproduction of cordycepin by two-stage dissolved oxygen control in submerged cultivation of medicinal mushroom Cordyceps militaris in bioreactors," Biotechnology Progress, vol. 20, no. 5, pp. 1408-1413, 2004.

[11] H. G. Kim, B. Shrestha, S. Y. Lim et al., "Cordycepin inhibits lipopolysaccharide-induced inflammation by the suppression of NF- $\kappa$ B through Akt and p38 inhibition in RAW 264.7 macrophage cells," European Journal of Pharmacology, vol. 545, no. 2-3, pp. 192-199, 2006.

[12] R. Yu, L. Wang, H. Zhang, C. Zhou, and Y. Zhao, "Isolation, purification and identification of polysaccharides from cultured Cordyceps militaris," Fitoterapia, vol. 75, no. 7-8, pp. 662-666, 2004.

[13] J. Y. Cho, K. U. Baik, J. H. Jung, and M. H. Park, "In vitro antiinflammatory effects of cynaropicrin, a sesquiterpene lactone, from Saussurea lappa," European Journal of Pharmacology, vol. 398, no. 3, pp. 399-407, 2000.

[14] J. G. Park, Y.-J. Son, A. Aravinthan, J.-H. Kim, and J. Y. Cho, "Korean red ginseng water extract arrests growth of xenografted lymphoma cells," Journal of Ginseng Research, vol. 40, no. 4, pp. 431-436, 2016.

[15] J. G. Park, W.-S. Kang, K. T. Park et al., "Anticancer effect of joboksansam, Korean wild ginseng germinated from bird feces," Journal of Ginseng Research, vol. 40, no. 3, pp. 304-308, 2016.

[16] Y. Yang, J. Lee, M. H. Rhee et al., "Molecular mechanism of protopanaxadiol saponin fraction-mediated anti-inflammatory actions," Journal of Ginseng Research, vol. 39, no. 1, pp. 61-68, 2015.

[17] M. S. Kim, Y. Lee, G.-H. Sung et al., "Pro-apoptotic activity of 4-isopropyl-2-(1-phenylethyl) aniline isolated from cordyceps bassiana," Biomolecules and Therapeutics, vol. 23, no. 4, pp. 367373, 2015.

[18] W. Suh, G. Nam, and W. S. Yang, "Chemical constituents identified from fruit body of Cordyceps bassiana and their antiinflammatory activity," Biomolecules Therapeutics, vol. 25, no. 2, pp. 165-170, 2016.

[19] K.-S. Baek, Y. D. Hong, Y. Kim et al., "Anti-inflammatory activity of AP-SF, a ginsenoside-enriched fraction, from Korean ginseng," Journal of Ginseng Research, vol. 39, no. 2, pp. 155-161, 2015.

[20] N. Y. Sung, S. C. Kim, and Y. H. Kim, "Anti-proliferative and pro-apoptotic activities of 4-methyl-2, 6-bis(1-phenylethyl)phenol in cancer Cells," Biomolecules Therapeutics, vol. 24, pp. 402409, 2016.

[21] J. H. Kim, Y. G. Lee, S. Yoo et al., "Involvement of Src and the actin cytoskeleton in the antitumorigenic action of adenosine dialdehyde," Biochemical Pharmacology, vol. 85, no. 8, pp. 10421056, 2013.

[22] S.-H. Hwang, B.-H. Lee, S.-H. Choi et al., "Effects of gintonin on the proliferation, migration, and tube formation of human umbilical-vein endothelial cells: Involvement of lysophosphatidic-acid receptors and vascular-endothelial-growth-factor signaling," Journal of Ginseng Research, vol. 40, no. 4, pp. 325333, 2016.
[23] K.-S. Baek, Y.-S. Yi, Y.-J. Son et al., "In vitro and in vivo antiinflammatory activities of Korean red Ginseng-derived components," Journal of Ginseng Research, vol. 40, no. 4, pp. 437-444, 2016.

[24] J. Y. Wu, Q. X. Zhang, and P. H. Leung, "Inhibitory effects of ethyl acetate extract of Cordyceps sinensis mycelium on various cancer cells in culture and B16 melanoma in C57BL/6 mice," Phytomedicine, vol. 14, no. 1, pp. 43-49, 2007.

[25] A. Thakur, R. Hui, Z. Hongyan, Y. Tian, C. Tianjun, and C. Mingwei, "Pro-apoptotic effects of Paecilomyces hepiali, a Cordyceps sinensis extract on human lung adenocarcinoma A549 cells in vitro," Journal of Cancer Research and Therapeutics, vol. 7, no. 4, pp. 421-426, 2011.

[26] C. Park, S. Hong, J. Lee et al., "Growth inhibition of U937 leukemia cells by aqueous extract of Cordyceps militaris through induction of apoptosis,' Oncology Reports, vol. 13, pp. 1211-1216, 2005.

[27] Q. Liu, H.-W. Dong, W.-G. Sun et al., "Apoptosis initiation of $\beta$ ionone in SGC-7901 gastric carcinoma cancer cells via a PI3KAKT pathway," Archives of Toxicology, vol. 87, no. 3, pp. 481-490, 2013.

[28] D. Ramljak, R. J. Calvert, P. W. Wiesenfeld et al., "A potential mechanism for fumonisin B1-mediated hepatocarcinogenesis: Cyclin D1 stabilization associated with activation of Akt and inhibition of GSK-3 $\beta$ activity," Carcinogenesis, vol. 21, no. 8, pp. 1537-1546, 2000.

[29] Y. Wu, Y. Shang, S. Sun, H. Liang, and R. Liu, "Erythropoietin prevents PC12 cells from 1-methyl-4-phenylpyridinium ioninduced apoptosis via the Akt/GSK-3 $\beta /$ caspase- 3 mediated signaling pathway," Apoptosis, vol. 12, no. 8, pp. 1365-1375, 2007.

[30] A. Gautreau, P. Poullet, D. Louvard, and M. Arpin, "Ezrin, a plasma membrane-microfilament linker, signals cell survival through the phosphatidylinositol 3-kinase/Akt pathway," Proceedings of the National Academy of Sciences of the United States of America, vol. 96, no. 13, pp. 7300-7305, 1999.

[31] D. P. Steensma, M. Timm, and T. E. Witzig, "Flow cytometric methods for detection and quantification of apoptosis," Novel Anticancer Drug Protocols, vol. 85, pp. 323-332, 2003. 


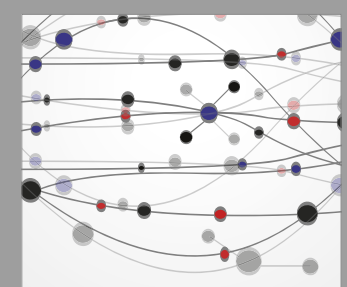

The Scientific World Journal
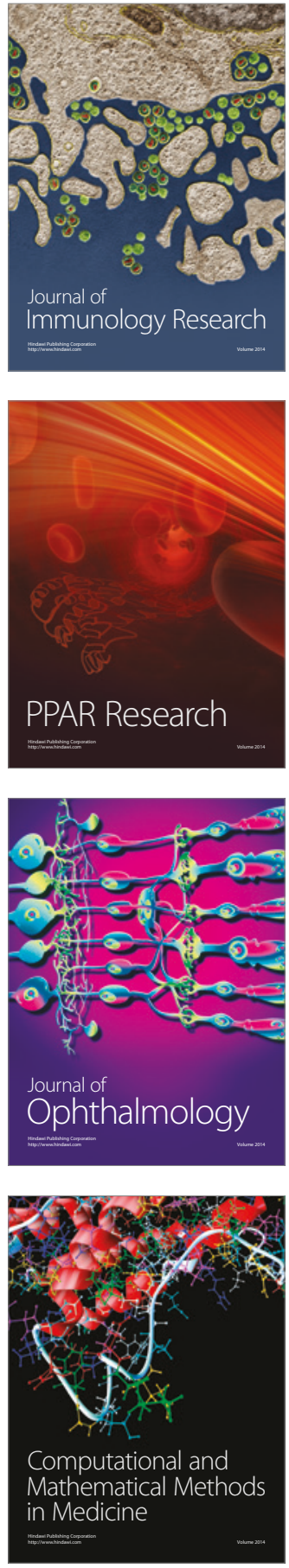

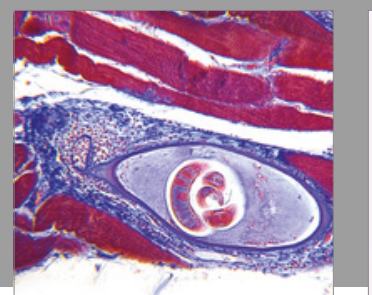

Gastroenterology Research and Practice
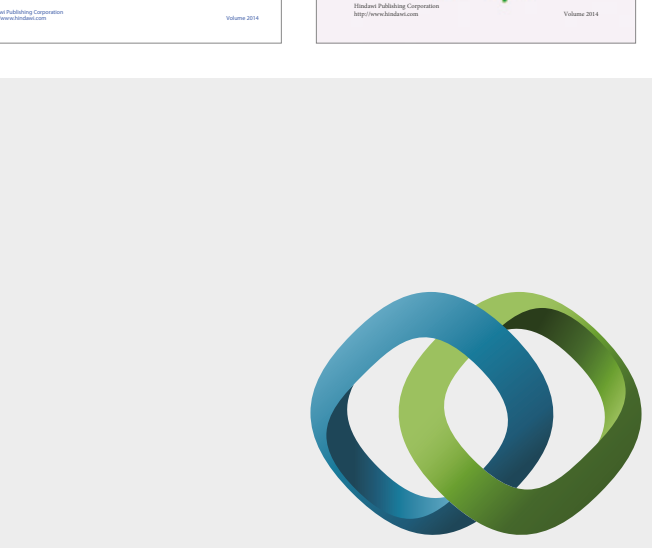

\section{Hindawi}

Submit your manuscripts at

https://www.hindawi.com
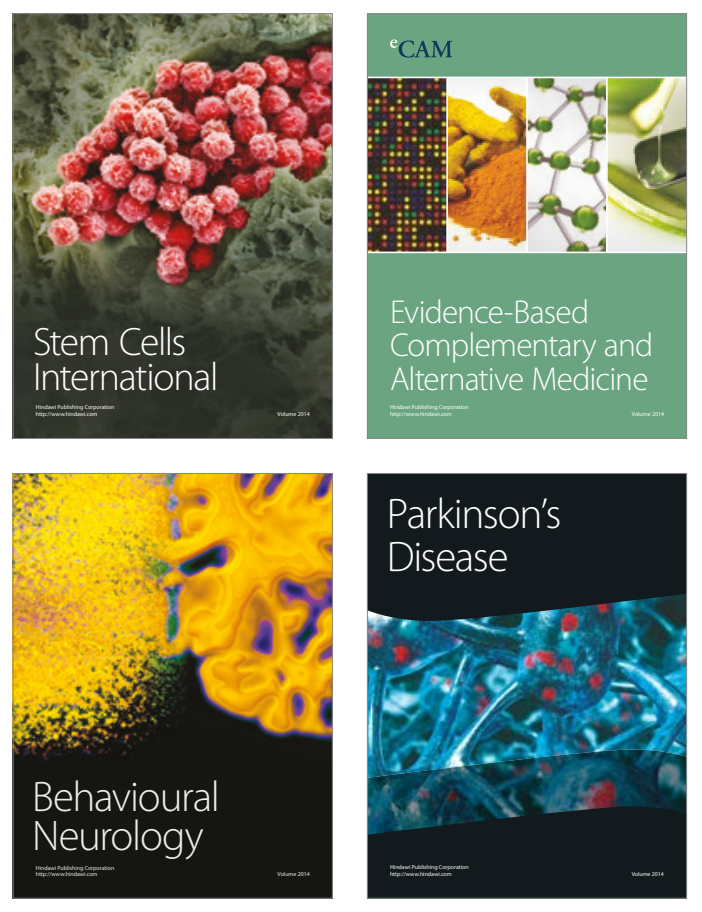
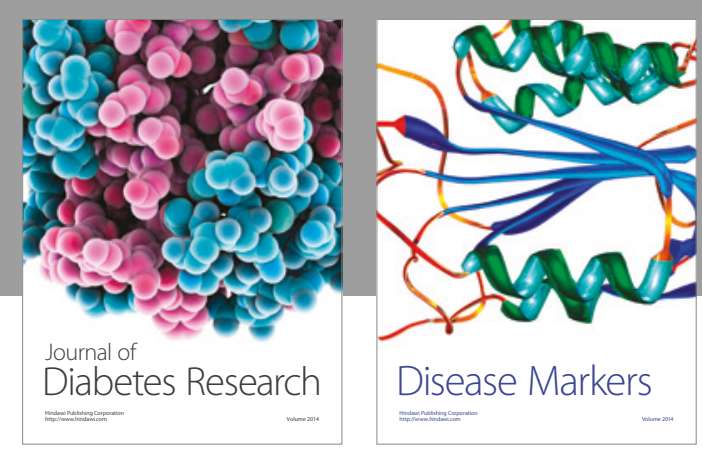

Disease Markers
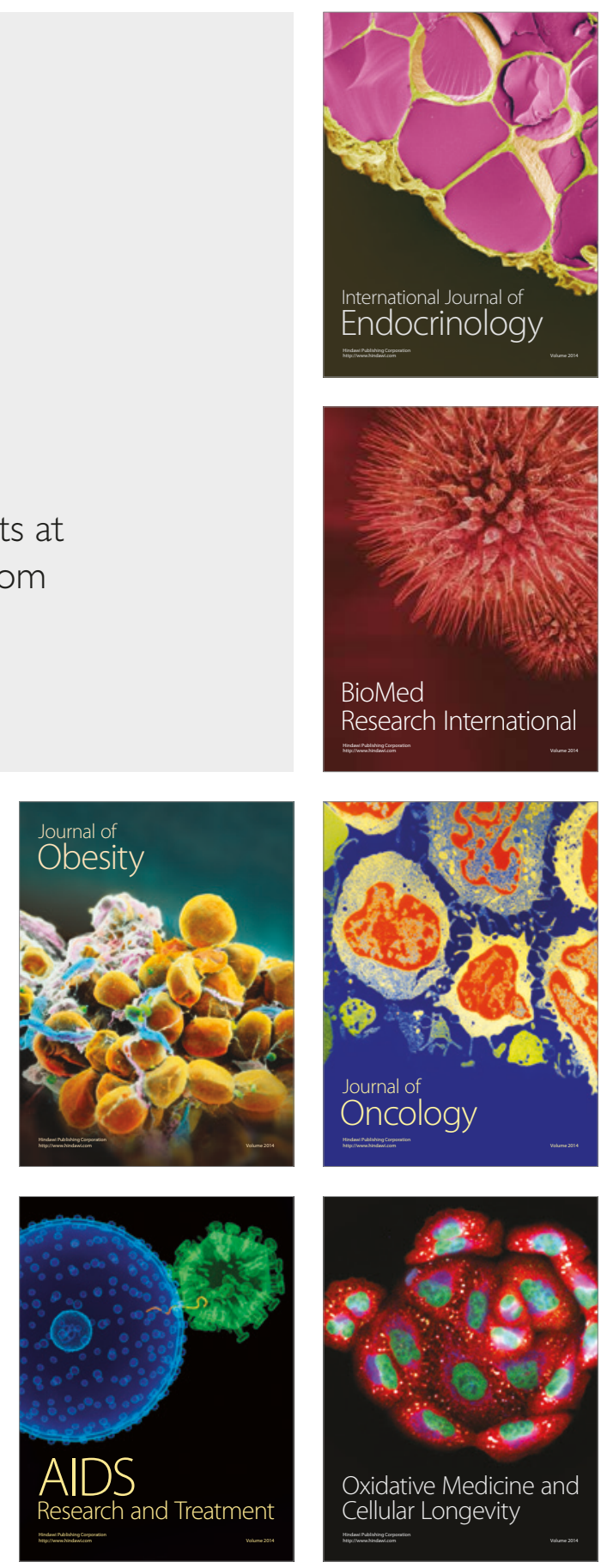